ARTICLE

https://doi.org/10.1038/s41467-020-18030-6

\title{
Probing consequences of anion-dictated electrochemistry on the electrode/monolayer/ electrolyte interfacial properties
}

\author{
Raymond A. Wong (10 ${ }^{1}$, Yasuyuki Yokota (iD) ${ }^{1,2 \times}$, Mitsuru Wakisaka ${ }^{3}$, Junji Inukai ${ }^{4}$ \& Yousoo Kim (iD) ${ }^{1 凶}$
}

\begin{abstract}
Altering electrochemical interfaces by using electrolyte effects or so-called "electrolyte engineering" provides a versatile means to modulate the electrochemical response. However, the long-standing challenge is going "beyond cyclic voltammetry" where electrolyte effects are interrogated from the standpoint of the interfacial properties of the electrode/electrolyte interface. Here, we employ ferrocene-terminated self-assembled monolayers as a molecular probe and investigate how the anion-dictated electrochemical responses are translated in terms of the electronic and structural properties of the electrode/monolayer/electrolyte interface. We utilise a photoelectron-based spectroelectrochemical approach that is capable of capturing "snapshots" into (1) anion dependencies of the ferrocene/ferrocenium ( $\mathrm{Fc} / \mathrm{Fc}^{+}$) redox process including ion-pairing with counter anions ( $\mathrm{Fc}^{+}$-anion) caused by differences in $\mathrm{Fc}^{+}$-anion interactions and steric constraints, and (2) interfacial energetics concerning the electrostatic potential across the electrode/monolayer/electrolyte interface. Our work can be extended to provide electrolyte-related structure-property relationships in redox-active polymers and functionalised electrodes for pseudocapacitive energy storage.
\end{abstract}

\footnotetext{
${ }^{1}$ Surface and Interface Science Laboratory, RIKEN, 2-1 Hirosawa, Wako, Saitama 351-0198, Japan. ${ }^{2}$ PRESTO, Japan Science and Technology Agency (JST), 4 1-8 Honcho, Kawaguchi, Saitama 332-0012, Japan. ${ }^{3}$ Graduate School of Engineering, Toyama Prefectural University, 5180 Kurokawa, Imizu, Toyama $939-$ 0398, Japan. ${ }^{4}$ Clean Energy Research Center, University of Yamanashi, 4-3-11 Takeda, Kofu, Yamanashi 400-8510, Japan. ${ }^{凶}$ email: yyokota@riken.jp; ykim@riken.jp
} 
C entral to electrochemistry is the constant pursuit to elucidate the underlying factors that govern the electrochemical response. The motivation stems from the desire to augment the functionality of devices by controllably altering key parameters such as the redox potential, reaction pathway, reversibility and stability. However, achieving this requires an intimate knowledge of the interfacial properties as this affects the charge transfer process and thus, the overall electrochemical response. This fuels the desire to obtain structure-property relationships that sufficiently encompasses the intricacies of the electrochemical environment at the electrode/electrolyte interface $^{1-4}$.

To this end, surface-confined redox molecules such as ferrocene-terminated alkanethiol self-assembled monolayers (Fc $\mathrm{SAM}$ ) on $\mathrm{Au}$ (Fig. 1) constitute an attractive molecular probe for correlative studies into interfacial electrochemistry and the physicochemical properties of the interface ${ }^{4-6}$. With relevance to bio (chemical) sensing ${ }^{7}$, redox-induced micro-actuators ${ }^{8}$ and molecular electronics 9 , the corresponding Fc termini can switch between neutral $\mathrm{Fc}$ (ferrocene) and cationic $\mathrm{Fc}^{+}$(ferrocenium) redox states via single-electron transfer and ion-pairing reactions with anions: $(\mathrm{Fc})_{\mathrm{SAM}}+\mathrm{X}^{-}$aq $\leftrightarrows\left(\mathrm{Fc}^{+}-\mathrm{X}^{-}\right)_{\mathrm{SAM}}+\mathrm{e}^{-10,11}$. Therefore, the anion should play an important role in the $\mathrm{Fc} / \mathrm{Fc}^{+}$redox process and has been shown to influence the apparent formal potential $\left(E^{o \prime}\right)$ and reversibility owing to the influence of anion solvation on the behaviour of ion pairing ${ }^{12,13}$. Concomitantly, this implies that the anion should affect the microscopic ion-pair structures ${ }^{14}$ and the related structural changes including monolayer thickness ${ }^{15,16}$ and molecular orientation ${ }^{17}$. While there are techniques that can probe such structural changes, we will show for the first time, the ability to also discriminate the aniondictated Fc SAM interfacial electronic properties.

A related aspect is the interfacial energetics as first envisioned by Helmholtz and later expanded by Gouy-Chapman and Stern ${ }^{4}$. The electrified electrode/electrolyte interface consists of a region with a linear potential gradient (inner Helmholtz plane) followed by the outer Helmholtz plane (diffuse layer) where the potential profile decays monotonically into the electrolyte. In the presence of a SAM, the linear potential portion is dependent on the length
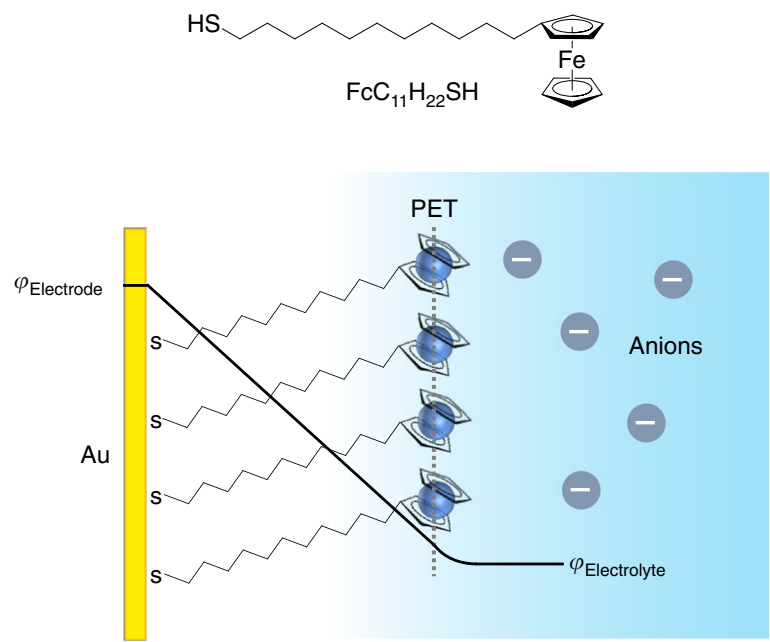

Fig. 1 Model system used as a molecular probe. Molecular structure of 11ferrocenyl-1-undecanethiol (top panel) that form ferrocene-terminated alkanethiol self-assembled monolayers (Fc SAM) on Au. Schematic representation (bottom panel) of the Fc SAM electrode/monolayer/ electrolyte interfacial region showing the interfacial potential distribution ( $\varphi$ ) from Au metal electrode to electrolyte. Plane of electron transfer is denoted as PET. of the molecules adsorbed on the electrode surface (Fig. 1) ${ }^{18-20}$. Existing studies aimed at corroborating these theories have predominantly relied on systematically varying the SAM structure. For instance, by varying the length of $n$-alkanethiols and measuring cyclic voltammetry (CV), Porter et al. showed that the role of interfacial capacitance can be indirectly inferred ${ }^{21}$. Eggers et al. demonstrated the relationship between the apparent formal potential and the height of the $\mathrm{Fc}$ termini relative to a coadsorbed non-electroactive $\mathrm{SAM}^{22}$. While varying the SAM structure can be an effective approach, methods that can directly interrogate the influence of the interfacial potential distribution have thus far, been very limited.

Our work aims to address these challenges by employing photoelectron spectroscopy in the X-ray and ultraviolet wavelengths (XPS/UPS). Based on the photoelectric effect, XPS/UPS detects the kinetic energy of ejected photoelectrons to reveal the electronic and chemical environment of atoms at the sample surface. However, an intrinsic obstacle is the need for vacuum conditions in order to obtain useful detection probabilities ${ }^{23}$. A workaround is to employ a so-called pseudo in situ UHV-EC approach originally conceived by Hubbard and coworkers ${ }^{24-29}$ to link the electrochemical (solution) and XPS/UPS (ultrahigh vacuum, UHV) environments (see Methods). We note that alternatively, true in situ XPS can offer another avenue to explore solid/liquid interfaces ${ }^{1,30-36}$, while each approach has noteworthy trade-offs such as signal-to-noise versus temporal resolution (see Supplementary Note 1). The UHV-EC approach used in the present study involves electrode immersion (Fig. 2a and Supplementary Fig. 1) where electrochemical measurements are performed in a dedicated chamber under Ar atmosphere. This is followed by removal under potential control and then transfer to vacuum to enable a "snapshot-like" analysis into the electrochemical-induced changes. Notable work using UHV-EC by Kolb and Hansen attributed the observation of systematic XPS binding energy shifts with electrode potential as an indicator that the electrochemically-induced changes (i.e. double layer) can be conserved following electrode immersion $1,2,26,37,38$.

Herein, we interrogate the Fc SAM molecular probe and show how the anion-dictated electrochemistry is conveyed in terms of the electronic and structural properties of the electrode/monolayer/ electrolyte interface. We predominantly focus on two anions, namely a bulky organic anion $\left(\left[\mathrm{CF}_{3} \mathrm{SO}_{2}\right]_{2} \mathrm{~N}^{-}\right.$, denoted as $\left.\mathrm{TFSI}^{-}\right)$ and an inorganic anion $\left(\mathrm{PF}_{6}{ }^{-}\right)$, which should invariably affect the ion-ion and ion-solvent interactions owing to differences in ionic size, charge density, polarisability and flexibility ${ }^{39}$. We use a spectroelectrochemical approach consisting of XPS/UPS combined with an electrochemical cell (denoted hereon as EC-XPS/UPS) to electrochemically control the Fc SAM followed by spectroscopic observations into the anion-dictated aspects of the $\mathrm{Fc} / \mathrm{Fc}^{+}$redox process including $\mathrm{Fc}^{+}-\mathrm{X}^{-}$ion-pairing, monolayer thickness, Fe oxidation state and valence structure. A key aspect of our findings is related to the $\mathrm{TFSI}^{-}$anion which uniquely restricts the $\mathrm{FC}^{+}$ reaction yield, thereby creating the conditions where the influence of the electrostatic potential across the electrode/monolayer/electrolyte interface is readily observable via concomitant core and valence-level binding energy shifts. The work presented here underscores how "beyond cyclic voltammetry" approaches consisting of vacuum-based methods can be effective in ascertaining the intricacies of the electrode/electrolyte interface.

\section{Results}

Anion-dictated electrochemical responses. Cyclic voltammograms (CVs) of Fc SAM on $\mathrm{Au}(111)$ in $0.1 \mathrm{M} \mathrm{NaTFSI}, \mathrm{NaPF}_{6}$ and $\mathrm{NaClO}_{4}$ (Fig. 2b) show that in addition to the apparent formal potentials $\left(E^{\prime \prime}\right)$, the nature of the anion also influences the degree of 
conversion to $\mathrm{Fc}^{+}$(reaction yield). Namely, the apparent formal potentials (Table 1) indicates that oxidation initiates at lower anodic potentials with $\mathrm{TFSI}^{-}(0.180 \mathrm{~V})$ followed by $\mathrm{PF}_{6}^{-}(0.240 \mathrm{~V})$ and $\mathrm{ClO}_{4}^{-}(0.270 \mathrm{~V})$, respectively. The integral charge from the CVs indicates the degree of conversion to $\mathrm{Fc}^{+}\left(\Gamma_{\mathrm{Fc} \rightarrow \mathrm{Fc}}{ }^{+}\right.$, Table 1 and Supplementary Fig. 2). The $\Gamma_{\mathrm{Fc} \rightarrow \mathrm{Fc}^{+}}+$exhibited by $\mathrm{TFSI}^{-}$is lower $\left(3.1 \times 10^{-10} \mathrm{~mol} \mathrm{~cm}{ }^{-2}\right)$ in comparison to $\mathrm{PF}_{6}{ }^{-}$and $\mathrm{ClO}_{4}{ }^{-}$, which are similar $\left(4.6-4.7 \times 10^{-10} \mathrm{~mol} \mathrm{~cm}^{-2}\right)$, while it should be noted that the theoretical Fc SAM coverage is $4.5 \times 10^{-10} \mathrm{~mol} \mathrm{~cm}^{-2}$ (assuming

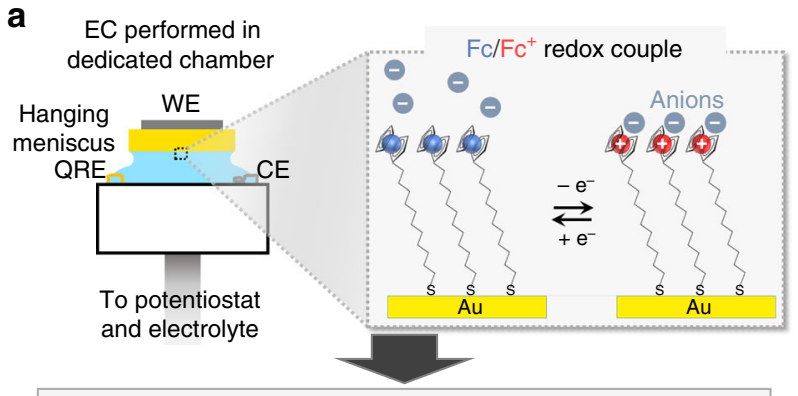

UHV-EC: Electrochemistry followed by transfer to XPS/UPS

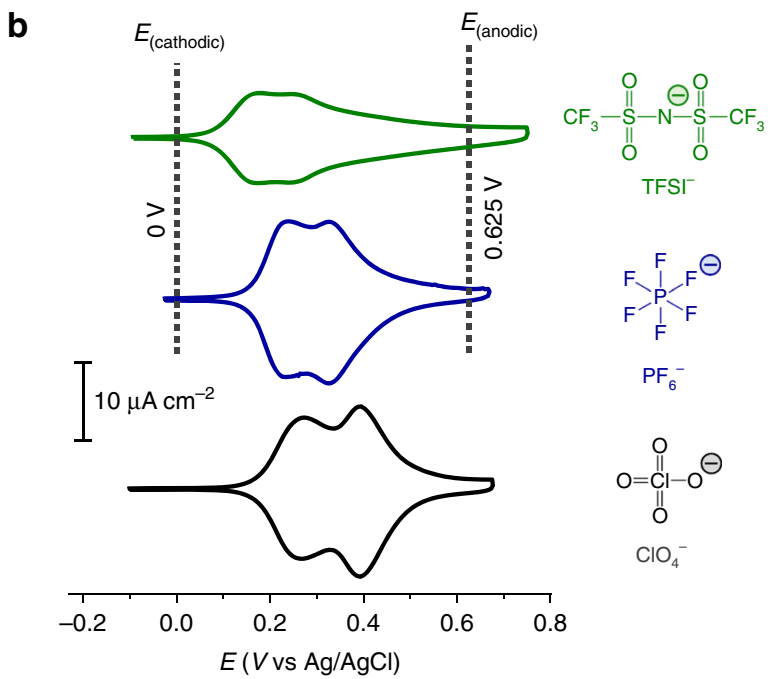

Fig. 2 Electrochemical cell setup and anion-dictated electrochemical responses. a $A$ schematic of the electrochemical $(E C)$ cell located inside a dedicated chamber where electrochemical measurements are performed under Ar atmosphere followed by evacuation and transfer to XPS/UPS chamber for analysis. The WE, QRE and CE denote the working, quasi reference and counter electrodes, respectively. See Methods and Supplementary Fig. 1 for details. b Steady state cyclic voltammograms (CVs) of Fc SAM on Au(111) performed in 0.1 M NaTFSI, NaPF 6 and $\mathrm{NaClO}_{4}$ at a scan rate of $50 \mathrm{mV} \mathrm{s}^{-1}$. The vertical dotted lines indicate the potentials 0.625 and $O V$, denoted as $E_{\text {(anodic) }}$ and $E_{\text {(cathodic), respectively }}$ which are the potentials the electrode was polarised for the EC-XPS/UPS measurements. close-packed Fc with a diameter of $0.66 \mathrm{~nm})^{5,40}$. All of the CVs are reversible (negligible anodic-cathodic peak separations) and all of the peak currents increase linearly with scan rate (Supplementary Fig. 3) thus, confirms that the Fc SAM are surface-confined to the $\mathrm{Au}$ electrode. It should be noted that all of the CVs exhibit non-ideal behaviour as seen by the multiple $\mathrm{CV}$ peaks that are commonly observed in close-packed Fc SAM ${ }^{41,42}$, and can be attributed to reasons including local heterogeneity and intermolecular interactions (see Supplementary Note 2 on non-ideal behaviour).

Occurrence of $\mathrm{Fc}^{+}-\mathrm{X}^{-}$ion-pairing and its reversibility. Subsequent spectroelectrochemical characterisations of the Fc SAM were performed on the pristine sample and after polarisation at 0.625 and $0 \mathrm{~V}$ (denoted as $E_{\text {(anodic) }}$ and $E_{\text {(cathodic) }}$ in Fig. 2b, respectively). These potentials provide an equal footing of comparison since $E_{\text {(anodic) }}$ and $E_{\text {(cathodic) }}$ can be expected to predominantly yield (neutral) $\mathrm{Fc}$ and oxidised (cationic) $\mathrm{Fc}^{+}$redox states, respectively. We primarily focus on contrasting $\mathrm{TFSI}^{-}$and $\mathrm{PF}_{6}{ }^{-}$ due to their distinct differences, whereas $\mathrm{ClO}_{4}^{-}$exhibits comparable $\mathrm{CV}$ characteristics to $\mathrm{PF}_{6}-40$.

The $\mathrm{Fc} / \mathrm{Fc}^{+}$redox reaction can be confirmed by observing the reversibility of $\mathrm{Fc}^{+}-\mathrm{X}^{-}$ion-pair formation and the structural changes of the electrode/monolayer/electrolyte interface. Oxidation to $\mathrm{Fc}^{+}$is accompanied by the formation of $\mathrm{Fc}^{+}-\mathrm{X}^{-}$ion-pairs due to the charge compensation of the charged $\mathrm{Fc}^{+}$by counter

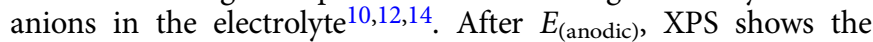
emergence of anion-related features resembling TFSI $^{-}$(Fig. 3a-c, $\mathrm{N}$ 1s, F 1s, $\mathrm{O}$ 1s) and $\mathrm{PF}_{6}^{-}$(Fig. 3d, e, P 2p and F 1s). These features diminish following $E_{\text {(cathodic) }}$ corresponding to the conversion back to $\mathrm{Fc}$, thus indicates the reversibility of $\mathrm{Fc}^{+}-\mathrm{X}^{-}$ ion pair formation. For both $\mathrm{TFSI}^{-}$and $\mathrm{PF}_{6}{ }^{-}$, the XPSdetermined stoichiometry (Supplementary Table 1) indicates the formation of $1: 1 \mathrm{Fc}^{+}-\mathrm{X}^{-}$ion pairs. However, in the case of $\mathrm{TFSI}^{-}$, it is important to note that the Fe: $\mathrm{N}$ : F atomic ratio of 1.2: 1.0: 6.0 is in line with $\Gamma_{\mathrm{Fc} \rightarrow \mathrm{Fc}}+$ obtained from the $\mathrm{CV}$ results (Fig. 2b) meaning that $\sim 70-80 \%$ of the $\mathrm{Fc}$ can be oxidised to $\mathrm{Fc}^{+}$. We note that this is consistent with the deconvoluted Fe $2 \mathrm{p}$ spectra (Supplementary Fig. 4 and vide infra). The partial conversion to $\mathrm{Fc}^{+}$suggests steric constraints of the bulkier $\mathrm{TFSI}^{-}$in comparison to $\mathrm{PF}_{6}{ }^{-}$(effective ionic radius of 0.33 and $0.25 \mathrm{~nm}$, respectively $)^{43-45}$. Complementary experiments examining competitive ion-pairing (mixed anions in Supplementary Fig. 5) and Fc SAM diluted with non-electroactive $n$-alkanethiols (Supplementary Fig. 6) supports this reasoning. Moreover, $E_{\text {(anodic) }}$ is met by a larger increase in effective monolayer thickness (Supplementary Fig. 7 and Supplementary Note 3 via Au $4 \mathrm{f}$ attenuation) with TFSI $^{-}(22.0 \pm 0.7 \AA)$ than $\mathrm{PF}_{6}^{-}(19.9 \pm 0.5 \AA)$, which implies differences in $\mathrm{Fc}^{+}-\mathrm{X}^{-}$ion-pair structure/size.

Our spectroelectrochemical observations are in line with electrochemical quartz crystal microbalance (EQCM) studies that have suggested that reversible 1:1 ion-pairing occurs in the presence of $\mathrm{ClO}_{4}{ }^{-}$anions ${ }^{46,47}$. Therefore, similar to the case with $\mathrm{ClO}_{4}^{-}$, the formation of $1: 1 \mathrm{Fc}^{+}-\mathrm{X}^{-}$contact ion-pairs is attributed to the hydrophobic (weakly solvating) nature of TFSI ${ }^{-}$

Table 1 Summary of Fc SAM electrochemical CV data for $\mathrm{TFSI}^{-}, \mathrm{PF}_{6}{ }^{-}$and $\mathrm{ClO}_{4}{ }^{-}$from Fig. $2 \mathrm{~b}$.

\begin{tabular}{llll} 
Anion & Apparent formal potential $\left(\boldsymbol{E}^{\prime}\right) \mathbf{~} \mathbf{V}$ vs. $\left.\mathbf{A g} / \mathbf{A g C l}\right)^{\mathbf{a}}$ & Integral charge transferred $\left(\boldsymbol{\Gamma}_{\mathbf{F c} \rightarrow \mathbf{F c}}{ }^{+}\right)\left(\mathbf{m o l}_{\mathbf{~ c m}}{ }^{-2}\right)^{\mathbf{b}}$ & $\boldsymbol{\Gamma}_{\mathbf{F c} \rightarrow \mathbf{F c}}{ }^{+} / \boldsymbol{\Gamma}_{\text {Thereotical }}(\mathbf{r a t i o}) \mathbf{c}$ \\
\hline $\mathrm{TFSI}^{-}$ & $0.180(0.240)$ & $3.1 \times 10^{-10}$ & $\sim 0.70$ \\
$\mathrm{PF}_{6}{ }^{-}$ & $0.240(0.330)$ & $4.6 \times 10^{-10}$ & $\sim 1.0$ \\
$\mathrm{ClO}_{4}{ }^{-}$ & $0.270(0.400)$ & $4.7 \times 10^{-10}$ & $\sim 1.0$ \\
\hline
\end{tabular}

${ }^{a} E^{\prime \prime}$ is the mean of the first set of anodic and cathodic peaks, while the parenthesis corresponds to the second set of peaks.

bUsed linear background subtraction between 0 and $0.625 \mathrm{~V}$.

${ }^{c} \Gamma_{\text {Theoretical }}$ is $4.5 \times 10^{-10} \mathrm{~mol} \mathrm{~cm}^{-2}$ (assuming close-packed Fc with a diameter of $0.66 \mathrm{~nm}$ ) 40 . 

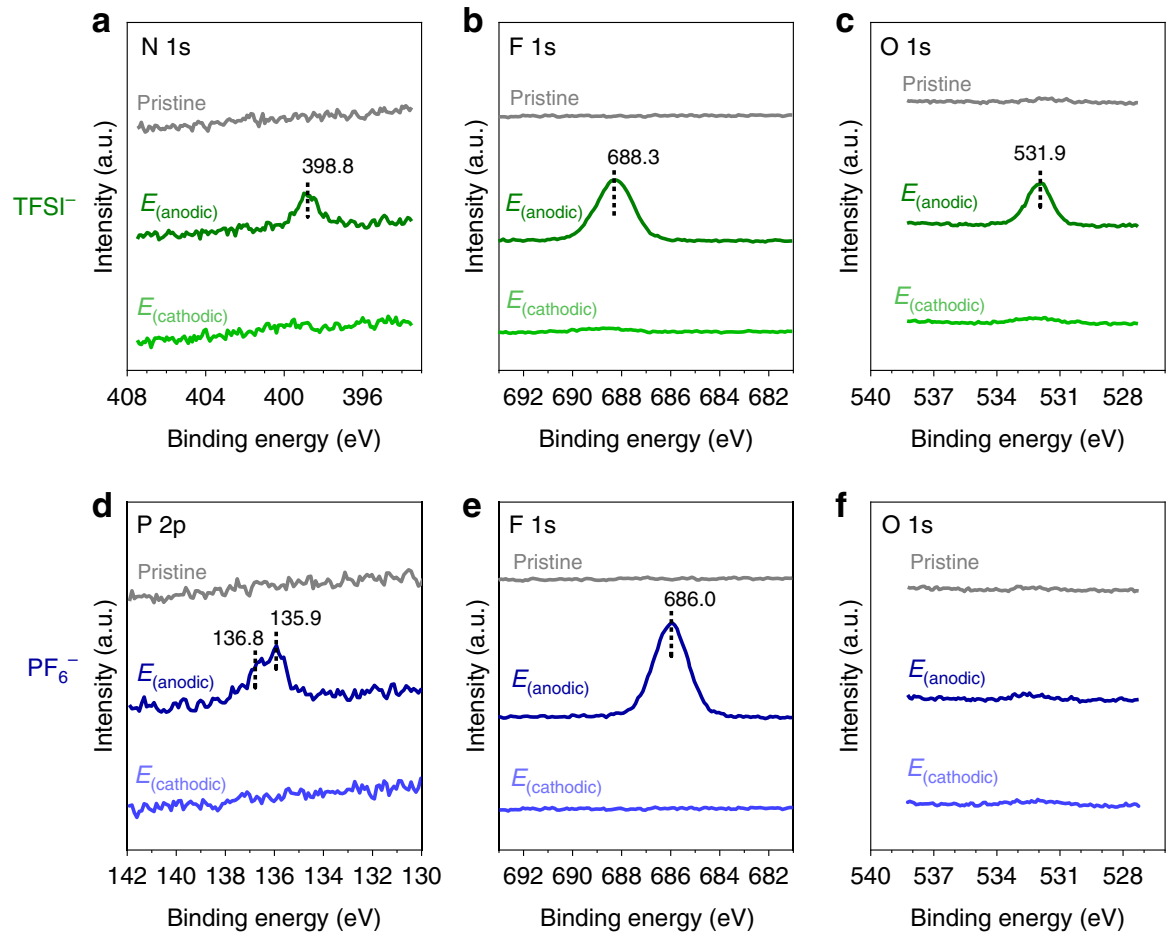

Fig. 3 Occurrence of $\mathbf{F} \mathbf{c}^{+}-\mathbf{X}^{-}$ion-pair formation and its reversibility. EC-XPS showing the anion spectra for pristine Fc SAM and following polarisation at 0.625 and $O \mathrm{~V}$, denoted as $E_{\text {(anodic) }}$ and $E_{\text {(cathodic) }}$ respectively, corresponding to $0.1 \mathrm{M} \mathrm{NaTFSI}$ a N 1s, b F 1s, c O 1s and $0.1 \mathrm{M} \mathrm{NaPF}$, d P 2p, e F 1s and $\mathbf{f} O$ 1s. Note that the S $2 p$ spectra is shown in Fig. 7a, b. XPS performed utilising Al $K \alpha, h v=1486.6 \mathrm{eV}$ at room temperature.
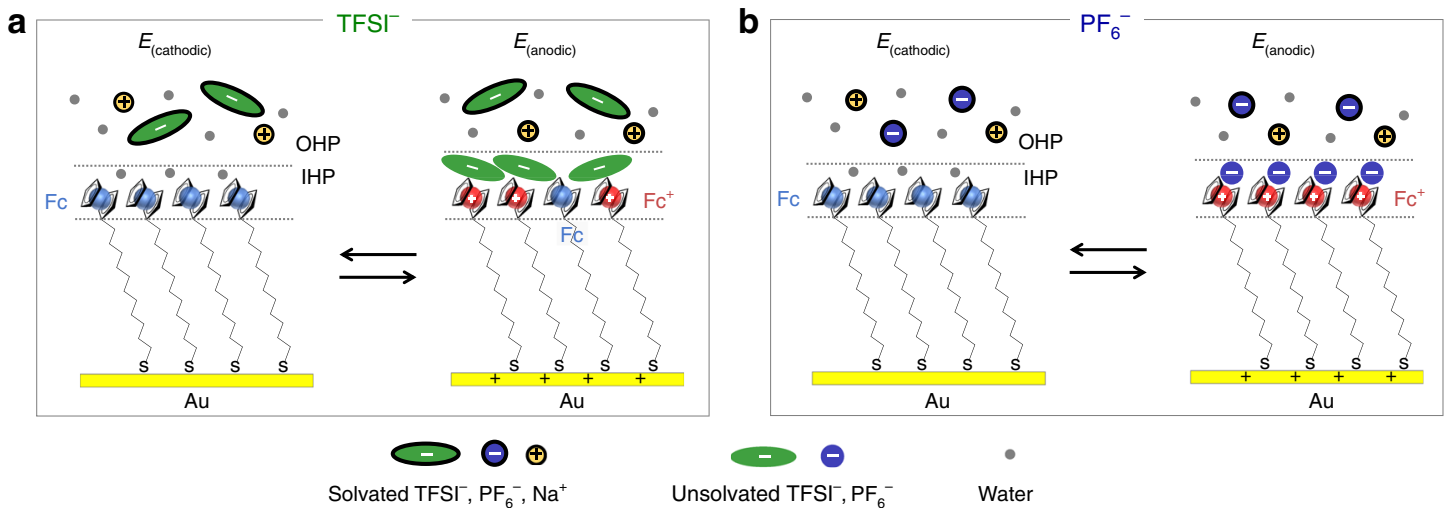

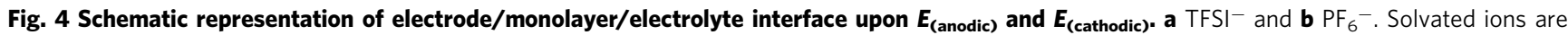
denoted by the encased black outline. IHP and OHP denote the inner and outer Helmholtz planes, respectively.

and $\mathrm{PF}_{6}{ }^{-}$, which strongly favours ion-pair formation to stabilise the charged $\mathrm{Fc}^{+}$. In addition, the $\mathrm{O} 1 \mathrm{~s}$ spectra for $\mathrm{PF}_{6}{ }^{-}$(contains no $O$ atoms) is largely featureless following $E_{\text {(anodic) }}$ and $E_{\text {(cathodic), }}$, while in the case of $\mathrm{TFSI}^{-}, \mathrm{O}$ 1s features are prominent only after $E_{\text {(anodic) }}$ which is attributed to TFSI $^{-}$forming the abovementioned $\mathrm{Fc}^{+}-\mathrm{X}^{-}$ion pairs. These $\mathrm{O}$ 1s spectral observations suggest that the immersion process "unzips" and eliminates weakly-interacting, excess electrolyte and that water is not strongly interacting with the immersed Fc SAM electrode ${ }^{48}$. We further note that $\left(\mathrm{Na}^{+}\right)$cation involvement in terms of charge compensation is found to be negligible at the potentials analysed (Supplementary Fig. 8, Na $1 \mathrm{~s}$ and $\mathrm{Na} 2 \mathrm{p}$ spectra). In all, the observation of reversible $1: 1 \mathrm{Fc}^{+}-\mathrm{X}^{-}$ion-pairing indicates that the electrochemically-induced changes are conserved following electrode immersion and transfer.

In light of the abovementioned observations, we can summarize the structural aspects of the electrode/monolayer/ electrolyte interface as schematically shown in Fig. 4. Polarisation at $E_{\text {(anodic) }}$ yields significant changes where the charged $\mathrm{Fc}^{+}$are effectively screened by counter anions at the inner Helmholtz plane resulting in a robust adlayer of $1: 1 \mathrm{Fc}^{+}-\mathrm{X}^{-}$contact ionpairs, and concomitantly leads to the increase in monolayer thickness. In terms of anion dependencies, in the case of $\mathrm{PF}_{6}{ }^{-}$, there are exclusively $1: 1 \mathrm{Fc}^{+}-\mathrm{PF}_{6}{ }^{-}$ion pairs, whereas in the case of $\mathrm{TFSI}^{-}, 1: 1 \mathrm{Fc}^{+}-\mathrm{TFSI}^{-}$ion pairs coexist with neutral $\mathrm{Fc}$ due to steric constraints ${ }^{45}$. On the other hand, for $E_{\text {(cathodic) }}$, the inner Helmholtz planes are structurally similar for both $\mathrm{TFSI}^{-}$and $\mathrm{PF}_{6}{ }^{-}$and consists of weakly-interacting water, while any ions that are present are expected to be solvated owing to the negligible surface charge.

However, despite reversible ion pairing, the anion-dictated apparent formal potentials are a reflection of differences in the ion-solvent and ion-ion interaction strengths. The resulting competition between the two dictates the favourability or 
tendency of $\mathrm{Fc}^{+}-\mathrm{X}^{-}$ion pairing. The tendency of ion-pairing can be empirically expressed as $K$ (ion-pair formation constant) in the following Nernst relation ${ }^{10}$ :

$$
E=E^{o}+2.303 \frac{\mathrm{RT}}{F} \log \frac{\left[\mathrm{Fc}^{+}-X^{-}\right]}{[\mathrm{Fc}] K}-2.303 \frac{\mathrm{RT}}{F} \log \left[X^{-}\right],
$$

where $E^{o}$ is the standard reduction potential and all other parameters have their usual meanings. Therefore, the apparent formal potential should depend on both $K$ and anion concentration $\left[\mathrm{X}^{-}\right]$. A plot of the apparent formal potential as a function of anion concentration (Supplementary Fig. 9) shows that all anions exhibit similar slopes of $2.303 \mathrm{RT} / F$ (equivalent to $\sim 60 \mathrm{mV}$ per decade), meaning that the difference in the vertical intercepts originates from the $K$ parameter. Based on the difference of the vertical intercepts $(\sim 60 \mathrm{mV})$, we can ascertain that the $K$ for TFSI $^{-}$is 10 times larger than in the case of $\mathrm{PF}_{6}{ }^{-}$. We note that alternatively, the ion-pairing tendencies and apparent formal potentials can be conceptually rationalised by invoking Pearson's hard-soft acid-base theory to explain $\mathrm{Fc}^{+}-\mathrm{X}^{-}$interactions based on the differences in the Lewis basicity of the anion ${ }^{49}$.

Electronic aspects of electrode/monolayer/electrolyte interface. We now move to the electronic aspects of the electrode/monolayer/electrolyte interface. The XPS Fe $2 p$ and UPS valence spectra (Fig. 5 and Supplementary Fig. 10) confirms that the pristine Fc SAM are indeed un-oxidised (neutral) $\mathrm{Fc}^{50}$. The sharp symmetry of the $\mathrm{Fe} 2 \mathrm{p}_{3 / 2}$ peak at $707.9 \mathrm{eV}$ (Fig. 5a, b) reflects the (low spin) diamagnetic character of $\mathrm{Fe}(\mathrm{II})^{50,51}$. Meanwhile, the
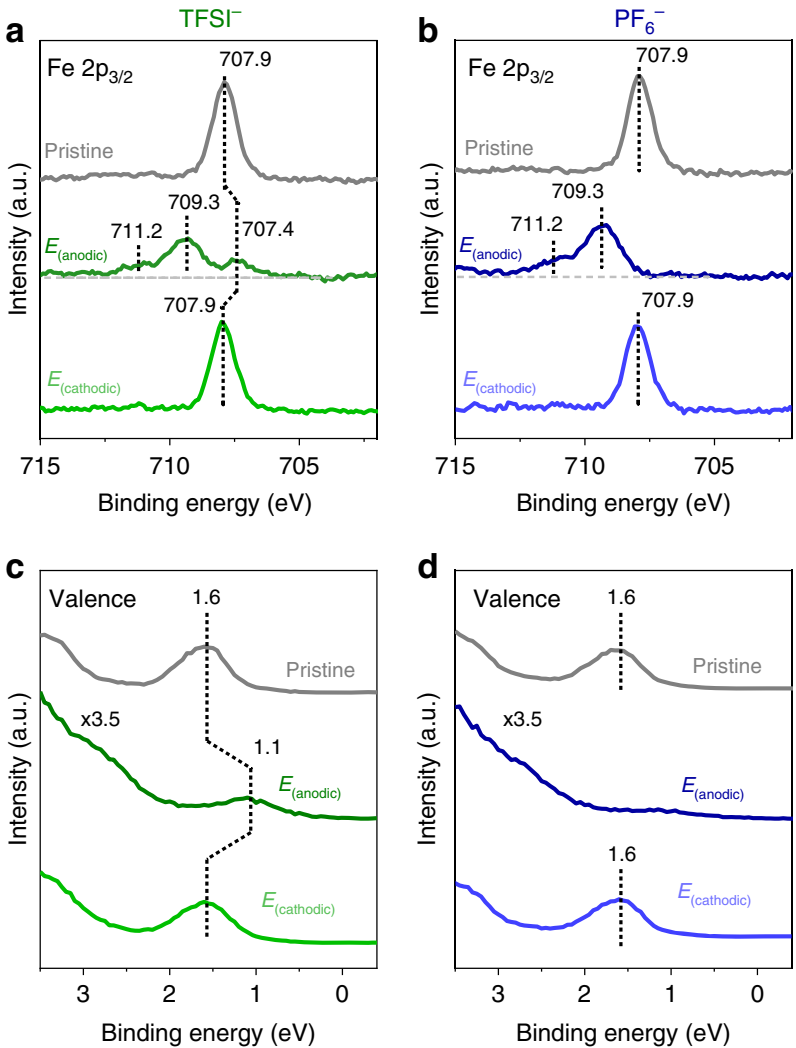

Fig. $5 \mathrm{Fc} / \mathrm{Fc}^{+}$redox centre and electrochemically-induced binding energy shifts. EC-XPS/UPS of pristine Fc SAM and following polarisation at $E_{\text {(anodic) }}$ and $E_{\text {(cathodic). }}$ a, b XPS Fe $2 p_{3 / 2}$ region for TFSI- (left panel) and $\mathrm{PF}_{6}{ }^{-}$(right panel). The deconvoluted Fe $2 \mathrm{p}_{3 / 2}$ spectra for $E_{\text {(anodic) }}$ is shown in Supplementary Fig. 4. c, d UPS valence spectra for TFSI- (left panel) and $\mathrm{PF}_{6}{ }^{-}$(right panel), respectively. The horizontal dashed lines act as a guide to the eyes.
UPS spectra shows a peak at $1.6 \mathrm{eV}$ (Fig. $5 \mathrm{c}$, $\mathrm{d}$ and Supplementary Fig. 11) ascribed to the highest occupied molecular orbital (HOMO) of Fc, comprised of the six 3d electrons from $\mathrm{Fe}^{51,52}$. Based on the geometry of the cyclopentadienyl $(\mathrm{Cp})$ ligands, $\mathrm{Fc}$ has the electronic configuration $\left(\mathrm{a}_{1}^{\prime}\right)^{2}\left(\mathrm{e}_{2}\right)^{4}$ and $\left(\mathrm{a}_{1 \mathrm{~g}}\right)^{2}\left(\mathrm{e}_{2 \mathrm{~g}}\right)^{4}$ for the eclipsed $\left(\mathrm{D}_{5 \mathrm{~h}}\right)$ and staggered $\left(\mathrm{D}_{5 \mathrm{~d}}\right)$ conformations, respectively ${ }^{53,54}$. The XPS Fe $2 p$ (core level) and UPS valence spectra can be tracked together because the Fc HOMO is localised to the Fe heteroatom causing them to be strongly correlated ${ }^{55,56}$.

Subsequent polarisation at $E_{\text {(anodic) }}$ leads to significant spectral changes with anion dependencies (Fig. 5). In both $\mathrm{TFSI}^{-}$and $\mathrm{PF}_{6}{ }^{-}$, oxidation is evidenced by the $\mathrm{Fe} 2 \mathrm{p}_{3 / 2}$ features at higher binding energy ( 709.3 eV in Fig. 5a, b and Supplementary Fig. 4) and is consistent with an increase in the Fe oxidation state to $\mathrm{Fe}$ (III). Also consistent with $\mathrm{Fe}(\mathrm{III})$ is the broadening and asymmetry of the $\mathrm{Fe} 2 \mathrm{p}_{3 / 2}$ peaks (notable shoulder at $711.2 \mathrm{eV}$ ) owing to final state effects including multiplet splitting caused by the presence of an unpaired valence electron in the (low spin) paramagnetic $\mathrm{Fe}(\mathrm{III})^{51,55}$. Note that in $\mathrm{TFSI}^{-}$, the remaining $\mathrm{Fe}$ (II) features $(707.4 \mathrm{eV})$ indicate residual Fc. Meanwhile, oxidation is also evident in the valence spectra (Fig. $5 c$, d), where the Fc HOMO peak diminishes in TFSI $^{-}$(indicates residual $\mathrm{Fc}$ ) and is clearly no longer prominent in the case of $\mathrm{PF}_{6}{ }^{-}$. The HOMO of the oxidised $\mathrm{Fc}^{+}$should be located at higher binding energy due to factors including increased Coulombic attraction but is likely overlapped by the anion and SAM-related features (i.e. alkyl chain and Au substrate) at binding energies $>2 \mathrm{eV}$ (Supplementary Fig. 11$)^{57}$. The extended valence spectra further supports differences in the interfacial ion-pair structures as seen by the pronounced $\mathrm{TFSI}^{-}$spectral features in the binding energy range 4-12 eV (Supplementary Fig. 11b), whereas in $\mathrm{PF}_{6}{ }^{-}$, the SAM features clearly remain. These observations show the uniqueness of the $\mathrm{Fc}^{+}-\mathrm{TFSI}^{-}$ion-pair structure which can strongly screen the SAM/Au spectral features.

In the case of $\mathrm{TFSI}^{-}$, a key observation is that the $\mathrm{Fe}(\mathrm{II})$ features in the Fe 2p core level and Fc HOMO (valence spectra) show systematic binding energy shifts with respect to the polarisation potential $\left(E_{\text {(cathodic) }}\right.$ and $\left.E_{\text {(anodic })}\right)$. Specifically, the $\mathrm{Fe}(\mathrm{II})$ peak in the $\mathrm{Fe} 2 \mathrm{p}_{3 / 2}$ spectra (Fig. 5a) is centred at 707.9 and $707.4 \mathrm{eV}$ for $E_{\text {(cathodic) }}$ and $E_{\text {(anodic), }}$, respectively. Similarly, in the valence spectra (Fig. 5c), the Fc HOMO peak is centred at 1.1 and $1.6 \mathrm{eV}$ for $E_{\text {(cathodic) }}$ and $E_{\text {(anodic), }}$ respectively. Taken together, this corresponds to a $\sim 0.8 \mathrm{eV} / \mathrm{V}$ relationship between binding energy shift and electrode potential. It should be noted that in terms of the intermediate potentials, EC-XPS/UPS measurements performed at increasing potentials with $\mathrm{ClO}_{4}{ }^{-}$(Supplementary Fig. 12) corroborates that the observed systematic binding energy shifts are linear.

These systematic XPS/UPS binding energy shifts are attributed to the influence of the electrostatic potential across the electrode/ monolayer/electrolyte interface ${ }^{2,20}$. The electrostatic potential profile is expected to be linear in accordance with the parallel plate capacitor model (Fig. 1) ${ }^{19,22}$ where the majority of the potential drop occurs within the monolayer (Supplementary Note 4 and Supplementary Fig. 13). Specifically, the binding energy shifts reflect the change in the potential difference between $\varphi_{\text {Electrode }}$ and $\varphi_{\text {Electrolyte }}$ (Fig. 1), and is related to the electrode potential $(\Delta E)$ as shown below: 19,58

$$
\Delta E=\Delta\left(\varphi_{\text {Electrode }}-\varphi_{\text {Electrolyte }}\right) .
$$

The binding energy shifts are observed because the binding energy is measured with respect to the Fermi level $\left(E_{\mathrm{Fermi}}\right)$ of the $\mathrm{Au}$ substrate which is the same entity as the electrode potential (illustrated in Fig. 6). Meanwhile, on the other side of the interface, the Fc termini are electronically decoupled from the substrate, and 

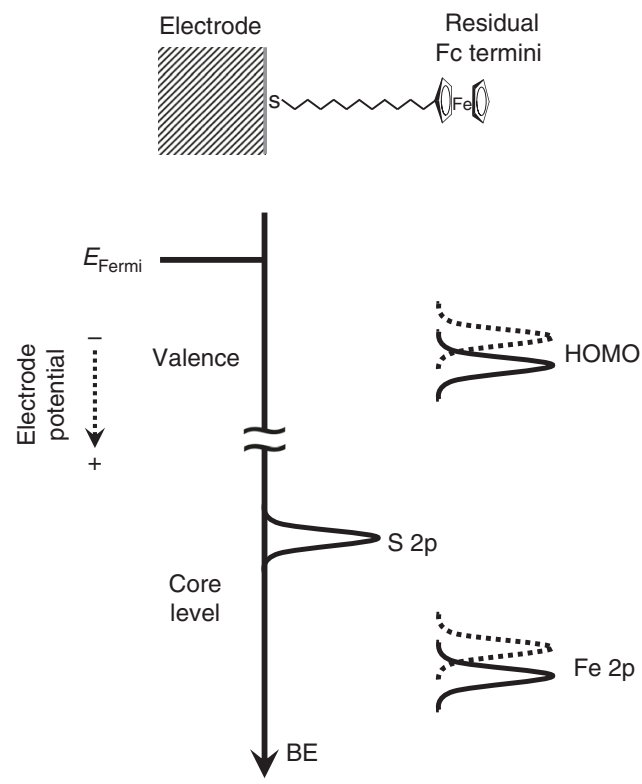

Fig. 6 Electrochemically-induced core and valence-level binding energy shifts. A schematic showing the relationship between Fermi level $\left(E_{\text {Fermi }}\right)$, electrode potential and the XPS/UPS binding energy shifts. BE denotes binding energy. The dotted lines denote the direction of the core and valence-level binding energy shifts that occur upon positive polarisation.
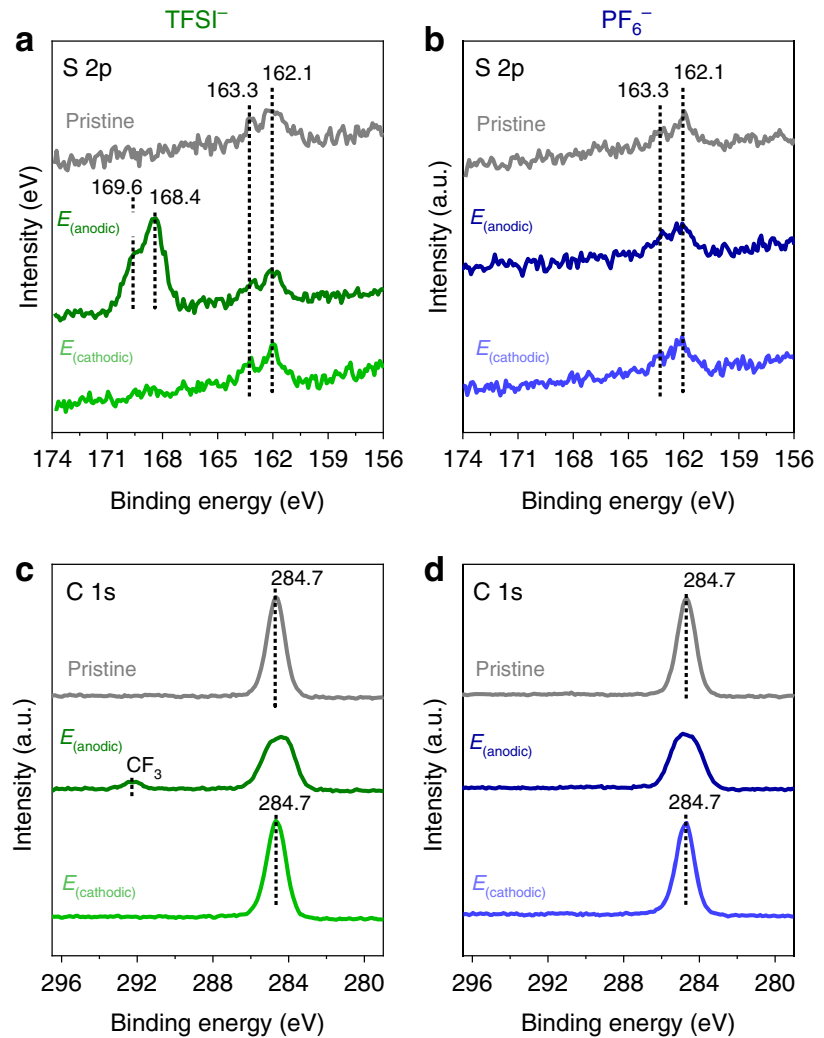

Fig. 7 Positional influence across electrode/monolayer/electrolyte interface. EC-XPS of the pristine Fc SAM and following polarisation at $E_{\text {(anodic) }}$ and $E_{\text {(cathodic) }}$ corresponding to the $S 2 p$ spectra for a TFSI- ${ }^{-}$and b $\mathrm{PF}_{6}{ }^{-}$. C $1 \mathrm{~s}$ spectra for $\mathbf{c}$ TFSI- and $\mathbf{d} \mathrm{PF}_{6}{ }^{-}$. Note in the case of TFSI-

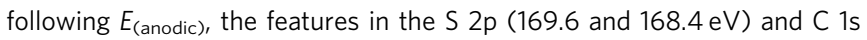
$\left(292.3 \mathrm{eV}\right.$ ) spectra are due to the $\mathrm{TFSI}^{-}$anion forming $\mathrm{Fc}^{+}-\mathrm{TFSI}^{-}$ion pairs (see text) ${ }^{51}$. therefore is referenced to the electrolyte $\left(\varphi_{\text {Electrolyte }}\right)^{2,20}$. The net effect of positive potential yields a lower binding energy, while negative potential yields higher binding energy (Fig. 6) ${ }^{20}$. Taken together, this means that the position within the monolayer relative to the $\mathrm{Au}$ electrode affects the binding energy shift ${ }^{20}$. This is consistent with the negligible binding energy shift in the $S 2 p$ spectral contributions from the bound thiolate (doublet at 163.3 and $162.1 \mathrm{eV}$ in Fig. $7 \mathrm{a}, \mathrm{b})^{50}$, irrespective of the polarisation potential because the anchoring $\mathrm{S}$ atoms are in close proximity to the $\mathrm{Au}$ electrode. It should be noted that following $E_{(\text {anodic) }}$ in TFSI $^{-}$, there is an additional S 2p doublet at 169.6 and $168.4 \mathrm{eV}$ (Fig. 7a) $)^{51}$ ascribed to the presence of TFSI $^{-}$anions forming ion-pairs (vide supra). The positioning within the monolayer is also ascribed as a contributing factor that causes the broadening of the $\mathrm{C}$ 1s spectra upon $E_{\text {(anodic) }}$ attributed to the $\mathrm{C}$ atoms located along the alkyl chain (Fig. 7c, d). We note that the $\sim 0.8 \mathrm{eV} / \mathrm{V}$ relationship is reasonably close to the expected $1 \mathrm{eV} / \mathrm{V}$ relationship ${ }^{2,26,38}$, and deviations can be caused by non-idealities such as buried Fc that have been reported to exist within the monolayer ${ }^{42,59}$.

\section{Discussion}

It is important to reiterate the role of $\mathrm{TFSI}^{-}$in creating an environment that inhibits the full conversion to $\mathrm{Fc}^{+}$leading to conditions where at XPS/UPS can readily probe the influence of the electrostatic potential across the electrode/monolayer/electrolyte interface. In addition, the Fe heteroatom is positioned at the edge of the electrode/monolayer/electrolyte interface which yields a clear electrostatic potential difference that can be readily probed. On the other hand, the interfacial environment in the case of $\mathrm{PF}_{6}^{-}$, causes the complete $\mathrm{Fc} / \mathrm{Fc}^{+}$conversion at the potentials analysed ( $E_{\text {(cathodic) }}$ and $\left.E_{\text {(anodic) }}\right)$ resulting in a discrete binding energy shift associated with oxidation, and thus masks the binding energy shift from the electrostatic potential. It is noteworthy to mention that in addition to the Fe heteroatom, the TFSI $^{-}$anion also exhibits binding energy shifts that are observable at an intermediate potential (Supplementary Fig. 14). This further supports that the edge of the electrode/monolayer/electrolyte interface is largely pinned to the electrostatic potential of the electrolyte $\left(\varphi_{\text {Electrolyte }}\right)$.

We now discuss the present work in the context of previous UHV-EC-based XPS studies that have reported electrochemically-induced binding energy shifts. These previous studies typically focus on bare metal electrodes restricted to the double-layer charging region ${ }^{2,26,38,60,61}$, whereas in our case, we utilise a reversible redox-active surface-bound molecular probe (Fc SAM). This difference has distinct advantages. The Fc SAM molecular probe offers a controlled, systematic approach since the number of $\mathrm{Fc} / \mathrm{Fc}^{+}$redox centres is well-defined throughout the experiments $\left(4.5 \times 10^{-10} \mathrm{~mol} \mathrm{~cm}{ }^{-2}\right)$ thus, allows the electrochemical response $(\mathrm{CV}$, charge transferred, and polarisation potential) to be directly correlated and verified with XPS/UPS regarding (1) the degree of $\mathrm{Fc}^{+}-\mathrm{X}^{-}$ion-pairing (anion coverage), (2) change of $\mathrm{Fc} / \mathrm{Fc}^{+}$redox centre (Fe oxidation state), and (3) binding energy shifts (Fe, anion, and valence spectra). This corroborative approach allows for more complete conclusions. Additionally, the construct of the Fc SAM molecular probe is beneficial because the alkyl chain physically and electronically separates the Fc termini from the electrode surface. This circumvents the challenges of existing studies where the influence of the high electric fields on species at the electrode surface can lead to ambiguities in the interpretation of the observed binding energy shifts ${ }^{61,62}$.

We add that the approach described here opens the door to other compelling opportunities including the modulation of the SAM structure, organic ions with strategically positioned 
heteroatoms $s^{9,63}$, use of ionic liquids as a coating or electrolyte ${ }^{55}$, or semiconducting electrodes ${ }^{64,65}$, which will alter the energetics of the electrode/monolayer/electrolyte interface. Our work shows a framework that can be extended to interrogate electrolyte effects and interfacial energetics in redox-active polymers ${ }^{66}$ and in applications relating to functionalised electrodes for pseudocapacitive energy storage ${ }^{67}$.

Using EC-XPS/UPS as a "beyond cyclic voltammetry" approach enables a unique spectroelectrochemical description of the anion-related electronic and structural properties of the electrode/monolayer/electrolyte interface which are not readily assessable with other methods. Upon anodic polarisation, we can spectroscopically discriminate differences in $\mathrm{Fc}^{+}-\mathrm{X}^{-}$ion-pair composition, monolayer thickness and degree of conversion to $\mathrm{Fc}^{+}$arising from $\mathrm{Fc}^{+}-\mathrm{X}^{-}$interactions and steric constraints, which manifests in the apparent formal potential and integral charge transferred as observed by $\mathrm{CV}$. Upon subsequent cathodic polarisation corresponding to the conversion back to $\mathrm{Fc}$, our observations are reversible. We have shown that the Fc SAM molecular probe construct enables a useful corroborative approach where the electrochemical response can be readily correlated to the XPS/UPS results allowing for the unobscured observation of the electrostatic potential at the electrode/monolayer/electrolyte interface. This work is part of our ongoing efforts to exploit UHV-EC methods to obtain a richer description of the electrode/electrolyte interface.

\begin{abstract}
Methods
Monolayer and substrate preparation. The cylindrical hat-shaped $\mathrm{Au}(111)$ substrates $(99.999 \%$, MaTecK) with a diameter of $6 \mathrm{~mm}$ were cleaned by soaking in piranha solution (concentrated $\mathrm{H}_{2} \mathrm{SO}_{4}$ (Kanto) and $30 \% \mathrm{H}_{2} \mathrm{O}_{2}$ (Wako) in a $3: 1$ volume ratio) at room temperature for at least $3 \mathrm{~h}$. Caution should be exercised because piranha solution is highly corrosive and vigorously reacts with organics meaning that a fume hood and uncovered vessel should be used. After soaking in piranha solution, the $\mathrm{Au}$ substrate was rinsed with copious amounts of Milli-Q water (18.2 $\mathrm{M} \Omega$, Millipore), dried under $\mathrm{N}_{2}$ gas flow and then flame annealed under a butane flame. The clean Au substrates were immersed for at least $12 \mathrm{~h}$ in ethanol (Wako) solutions containing $0.1 \mathrm{mM} 11$-ferrocenyl-1-undecanethiol (Dojindo Laboratories) followed by rinsing with ethanol and drying under a stream of $\mathrm{N}_{2}$ gas. For the mixed SAM/dilution experiments, an as-prepared SAM from $1 \mathrm{mM}$ 1-decanethiol (Aldrich) in ethanol was subsequently submerged in $0.1 \mathrm{mM}$ 11-ferrocenyl-1-undecanethiol (in ethanol) for at least 30 mins followed by rinsing with ethanol and drying under a stream of $\mathrm{N}_{2}$ gas. The $\mathrm{Au}(111)$ roughness factor was found to be good agreement with the literature which was determined to be $\sim 1.3$, based on the charge for the reduction of Au oxide $\left(444 \mu \mathrm{Ccm}^{-2}\right)^{68}$.
\end{abstract}

Photoelectron spectroscopy combined with an electrochemical cell. Our setup of X-ray and ultraviolet photoelectron spectroscopy combined with and electrochemical cell (EC-XPS/UPS) is similar in working principle to existing UHVEC reports that involve electrochemistry in a solution environment followed by transfer to a vacuum environment for analysis (Fig. 2a and Supplementary Fig. 1$)^{2,24,25,69}$. The XPS/UPS analysis chamber is connected via gate valve to an EC chamber allowing for sample transfer and electrochemical measurements without exposure to air. The EC chamber contains a retractable PTFE (polytetrafluorethylene) cell where electrochemical measurements are performed under Ar atmosphere (99.999\%, Tomoe Shokai). The cell utilises a hanging meniscus setup connected via PFA (perfluoroalkoxy alkane) tubing to a syringe containing the electrolyte. The typical EC-XPS/UPS experiment involves (1) Transfer of Fc SAM on Au sample to the electrochemical (EC) chamber under vacuum (2) Venting the EC chamber with Ar (3) Insertion of cell with electrolyte allowing for electrode immersion and electrochemical characterisations (4) Removal of the immersed electrode from the electrolyte solution under potential control (5) EC chamber evacuation and subsequent transfer to the XPS/UPS analysis chamber. The EC chamber evacuation and transfer occurs in $\sim 10 \mathrm{~min}$. The XPS/UPS (Theta Probe, Thermo Fisher Scientific) consists of a monochromatic $\mathrm{Al} K \alpha \mathrm{X}$-ray source $(h v=1486.6 \mathrm{eV})$ with a detection angle of $53^{\circ}$ relative to the normal. The base pressure of the XPS/UPS analysis chamber was $\sim 10^{-7} \mathrm{~Pa}$. XPS was performed at room temperature $(298 \mathrm{~K})$ using a pass energy setting of $100 \mathrm{eV}$. The binding energies are referenced to the $\mathrm{Au} 4 \mathrm{f}_{7 / 2}$ peak at $84.0 \mathrm{eV}$. Spectral fitting was done using Advantage 5.52 (Thermo Fisher) software using a Shirley background subtraction with Lorentzian and Gaussian ratio of 70:3055. Scofield sensitivity factors ${ }^{70}$ were used for quantification. The UV source uses $\mathrm{He}$ (I) excitation $(21.2 \mathrm{eV})$. UPS was performed with pass energy of $2 \mathrm{eV}$ with the spectra referenced to the Fermi edge of $\mathrm{Au}$ at $0 \mathrm{eV}$. A bias of $-10 \mathrm{~V}$ was applied to resolve the secondary electron cutoff. The $\mathrm{CV}$ and chronoamperometry electrochemical measurements (HZ-7000 potentiostat, Hokuto Denko) were performed at room temperature $\left(25^{\circ} \mathrm{C}\right)$. The electrolytes consisted of $0.1 \mathrm{M}$ NaTFSI (sodium bis(trifluoromethanesulfonyl)imide, $>98 \%$, TCI Chemicals), $\mathrm{NaPF}_{6}(99.7 \%$, Wako) or $\mathrm{NaClO}_{4}\left(99.99 \% \mathrm{NaClO}_{4} \cdot \mathrm{H}_{2} \mathrm{O}\right.$, Merck) that were prepared using DI water. The electrolytes were bubbled with Ar for at least 25 min prior to use. The counter electrode consists of a coiled Pt wire and the reference electrode is an $\mathrm{AuO}_{x}$ wire with the data converted to $\mathrm{Ag} / \mathrm{AgCl}$ (sat. $\mathrm{KCl}$ ) for comparison.

\section{Data availability}

The data that support the findings of this study are available from the corresponding authors upon reasonable request.

Received: 28 April 2020; Accepted: 28 July 2020;

Published online: 21 August 2020

\section{References}

1. Zaera, F. Probing liquid/solid interfaces at the molecular level. Chem. Rev. 112, 2920-2986 (2012).

2. Kolb, D. M. Electrochemical surface science. Angew. Chem. Int. Ed. 40, 1162-1181 (2001)

3. Magnussen, O. M. \& Groß, A. Toward an atomic-scale understanding of electrochemical interface structure and dynamics. J. Am. Chem. Soc. 141, 4777-4790 (2019)

4. Bard, A. J. et al. The electrode/electrolyte interface-a status report. J. Phys. Chem. 97, 7147-7173 (1993).

5. Chidsey, C. E., Bertozzi, C. R., Putvinski, T. \& Mujsce, A. Coadsorption of ferrocene-terminated and unsubstituted alkanethiols on gold: electroactive self-assembled monolayers. J. Am. Chem. Soc. 112, 4301-4306 (1990).

6. Eckermann, A. L., Feld, D. J., Shaw, J. A. \& Meade, T. J. Electrochemistry of redox-active self-assembled monolayers. Coord. Chem. Rev. 254, 1769-1802 (2010).

7. Mayall, R. M. et al. Enhanced signal amplification in a toll-like receptor-4 biosensor utilizing ferrocene-terminated mixed monolayers. ACS Sens. 4, 143-151 (2018).

8. Norman, L. L. \& Badia, A. Redox actuation of a microcantilever driven by a self-assembled ferrocenylundecanethiolate monolayer: an investigation of the origin of the micromechanical motion and surface stress. J. Am. Chem. Soc. 131, 2328-2337 (2009).

9. Yuan, L. et al. Controlling the direction of rectification in a molecular diode Nat. Commun. 6, 6324 (2015).

10. Uosaki, K., Sato, Y. \& Kita, H. Electrochemical characteristics of a gold electrode modified with a self-assembled monolayer of ferrocenylalkanethiols. Langmuir 7, 1510-1514 (1991).

11. Rowe, G. K. \& Creager, S. E. Redox and ion-pairing thermodynamics in selfassembled monolayers. Langmuir 7, 2307-2312 (1991).

12. Valincius, G. et al. Anion effect on mediated electron transfer through ferrocene-terminated self-assembled monolayers. Langmuir 20, 6631-6638 (2004).

13. Norman, L. L. \& Badia, A. Microcantilevers modified with ferroceneterminated self-assembled monolayers: effect of molecular structure and electrolyte anion on the redox-induced surface stress. J. Phys. Chem. C. 115, 1985-1995 (2010)

14. Yokota, Y., Yamada, T. \& Kawai, M. Ion-pair formation between ferroceneterminated self-assembled monolayers and counteranions studied by force measurements. J. Phys. Chem. C. 115, 6775-6781 (2011).

15. Feng, Y., Dionne, E. R., Toader, V., Beaudoin, G. \& Badia, A. Odd-even effects in electroactive self-assembled monolayers investigated by electrochemical surface plasmon resonance and impedance spectroscopy. J. Phys. Chem. C 121, 24626-24640 (2017).

16. Yao, X., Wang, J., Zhou, F., Wang, J. \& Tao, N. Quantification of redoxinduced thickness changes of 11-ferrocenylundecanethiol self-assembled monolayers by electrochemical surface plasmon resonance. J. Phys. Chem. B 108, 7206-7212 (2004).

17. Ye, S., Sato, Y. \& Uosaki, K. Redox-induced orientation change of a selfassembled monolayer of 11-ferrocenyl-1-undecanethiol on a gold electrode studied by in situ FT-IRRAS. Langmuir 13, 3157-3161 (1997).

18. Finklea, H. O. in Electroanalytical Chemistry: A Series of Advances Vol. 26 (eds Bard, A. J. \& Rubenstein, I.) 109-335 (Marcel Dekker, New York, 1996).

19. Smith, C. P. \& White, H. S. Theory of the interfacial potential distribution and reversible voltammetric response of electrodes coated with electroactive molecular films. Anal. Chem. 64, 2398-2405 (1992). 
20. Zhou, W. \& Kolb, D. M. Influence of an electrostatic potential at the metal/ electrolyte interface on the electron binding energy of adsorbates as probed by X-ray photoelectron spectroscopy. Surf. Sci. 573, 176-182 (2004).

21. Porter, M. D., Bright, T. B., Allara, D. L. \& Chidsey, C. E. Spontaneously organized molecular assemblies. 4. Structural characterization of n-alkyl thiol monolayers on gold by optical ellipsometry, infrared spectroscopy, and electrochemistry. J. Am. Chem. Soc. 109, 3559-3568 (1987).

22. Eggers, P. K., Darwish, N., Paddon-Row, M. N. \& Gooding, J. J. Surface-bound molecular rulers for probing the electrical double layer. J. Am. Chem. Soc. 134, 7539-7544 (2012).

23. Foelske-Schmitz, A. in Encyclopedia of Interfacial Chemistry (ed. Wandelt, K.) 591-606 (Elsevier, Amsterdam, 2018).

24. Soriaga, M. P. Ultra-high vacuum techniques in the study of single-crystal electrode surfaces. Prog. Surf. Sci. 39, 325-443 (1992)

25. Wakisaka, M. et al. Electronic structures of $\mathrm{Pt}-\mathrm{Co}$ and $\mathrm{Pt}-\mathrm{Ru}$ alloys for COtolerant anode catalysts in polymer electrolyte fuel cells studied by EC-XPS. J. Phys. Chem. B 110, 23489-23496 (2006).

26. Kolb, D. UHV techniques in the study of electrode surfaces. Z. Phys. Chem. 154, 179-199 (1987).

27. Ishikawa, R. M. \& Hubbard, A. T. Study of platinum electrodes by means of thin layer electrochemistry and low-energy electron diffraction 0: Part I. Electrode surface structure after exposure to water and aqueous electrolytes. $J$. Electroanal. Chem. Interfacial Electrochem. 69, 317-338 (1976).

28. Schnaidt, J. et al. A combined UHV-STM-flow cell set-up for electrochemical/ electrocatalytic studies of structurally well-defined UHV prepared model electrodes. Phys. Chem. Chem. Phys. 19, 4166-4178 (2017).

29. Foelske-Schmitz, A., Weingarth, D. \& Kötz, R. Quasi in situ XPS study of electrochemical oxidation and reduction of highly oriented pyrolytic graphite in [1-ethyl-3-methylimidazolium] $\left[\mathrm{BF}_{4}\right]$ electrolytes. Electrochim. Acta 56, 10321-10331 (2011).

30. Salmeron, M. \& Schlögl, R. Ambient pressure photoelectron spectroscopy: a new tool for surface science and nanotechnology. Surf. Sci. Rep. 63, 169-199 (2008).

31. Starr, D. E., Liu, Z., Hävecker, M., Knop-Gericke, A. \& Bluhm, H. Investigation of solid/vapor interfaces using ambient pressure $\mathrm{X}$-ray photoelectron spectroscopy. Chem. Soc. Rev. 42, 5833-5857 (2013).

32. Ketteler, G. et al. The nature of water nucleation sites on $\mathrm{TiO}_{2}(110)$ surfaces revealed by ambient pressure X-ray photoelectron spectroscopy. J. Phys. Chem. C. 111, 8278-8282 (2007).

33. Crumlin, E. J. et al. X-ray spectroscopy of energy materials under in situ/ operando conditions. J. Electron Spectrosc. Relat. Phenom. 200, 264-273 (2015).

34. Favaro, M. et al. Interface science using ambient pressure hard X-ray photoelectron spectroscopy. Surfaces 2, 78-99 (2019).

35. Masuda, T. et al. In situ X-ray photoelectron spectroscopy for electrochemical reactions in ordinary solvents. Appl. Phys. Lett. 103, 111605 (2013).

36. Casalongue, H. S. et al. Direct observation of the oxygenated species during oxygen reduction on a platinum fuel cell cathode. Nat. Commun. 4, 1-6 (2013).

37. Hansen, W. N. The emersed double layer. J. Electroanal. Chem. 150, 133-140 (1983).

38. D’Agostino, A. T. \& Hansen, W. N. Observation of systematic electrochemically induced binding energy shift in the XPS spectra of emersed $\mathrm{Cs}^{+}$double layer species. Surf. Sci. 165, 268-276 (1986).

39. Filippini, G., Goujon, F., Bonal, C. \& Malfreyt, P. Environment effect on the redox properties of Self-Assembled Monolayers: a theoretical investigation of the nature of the supporting electrolyte. Soft Matter 7, 8961-8968 (2011).

40. Rudnev, A. V. et al. Ferrocene-terminated alkanethiol self-assembled monolayers: An electrochemical and in situ surface-enhanced infra-red absorption spectroscopy study. Electrochim. Acta 107, 33-44 (2013).

41. Lee, L. Y. S., Sutherland, T. C., Rucareanu, S. \& Lennox, R. B. Ferrocenylalkylthiolates as a probe of heterogeneity in binary self-assembled monolayers on gold. Langmuir 22, 4438-4444 (2006).

42. Nerngchamnong, N. et al. Nonideal electrochemical behavior of ferrocenyl-alkanethiolate SAMs maps the microenvironment of the redox unit. J. Phys. Chem. C. 119, 21978-21991 (2015).

43. Ue, M. Mobility and ionic association of lithium and quaternary ammonium salts in propylene carbonate and $\gamma$-butyrolactone. J. Electrochem. Soc. 141, 3336-3342 (1994).

44. Asai, T., Kitada, A., Utsunomiya, T., Fukami, K. \& Murase, K. Redox of ferrocenylthiol SAMs in electrolytes with bis [(trifluoromethyl) sulfonyl] amide as unique anions: Parallel between aqueous and ionic liquid media. $J$. Electroanal. Chem. 795, 75-80 (2017).

45. Sun, Q.-W., Murase, K., Ichii, T. \& Sugimura, H. Anionic effect of ionic liquids electrolyte on electrochemical behavior of ferrocenylthiol/alkanethiol binary SAMs. J. Electroanal. Chem. 643, 58-66 (2010).

46. Shimazu, K., Yagi, I., Sato, Y. \& Uosaki, K. Electrochemical quartz crystal microbalance studies of self-assembled monolayers of 11-ferrocenyl-1- undecanethiol: structure-dependent ion-pairing and solvent uptake. J. Electroanal. Chem. 372, 117-124 (1994).

47. Ye, S., Haba, T., Sato, Y., Shimazu, K. \& Uosaki, K. Coverage dependent behavior of redox reaction induced structure change and mass transport at an 11-ferrocenyl-1-undecanethiol self-assembled monolayer on a gold electrode studied by an insitu IRRAS-EQCM combined system. Phys. Chem. Chem. Phys. 1, 3653-3659 (1999).

48. Bockris, J. O. M. \& Khan, S. U. M. Surface Electrochemistry: A Molecular Level Approach (Plenum, US, 1993).

49. Pearson, R. G. Hard and soft acids and bases, HSAB, part 1: fundamental principles. J. Chem. Educ. 45, 581 (1968).

50. Yokota, Y. et al. Comparative studies of photoelectron spectroscopy and voltammetry of ferrocene-terminated self-assembled monolayers possessing different electron-donating abilities. J. Phys. Chem. C. 118, 10936-10943 (2014).

51. Taylor, A. W. \& Licence, P. X-Ray photoelectron spectroscopy of ferrocenyl-and ferrocenium-based ionic liquids. ChemPhysChem 13, 1917-1926 (2012).

52. Mendez De Leo, L. P., de la Llave, E., Scherlis, D. \& Williams, F. J. Molecular and electronic structure of electroactive self-assembled monolayers. J. Chem. Phys. 138, 114707 (2013)

53. Xu, Z.-F., Xie, Y., Feng, W.-L. \& Schaefer, H. F. Systematic investigation of electronic and molecular structures for the first transition metal series metallocenes $\mathrm{M}\left(\mathrm{C}_{5} \mathrm{H}_{5}\right)_{2}(\mathrm{M}=\mathrm{V}, \mathrm{Cr}, \mathrm{Mn}, \mathrm{Fe}, \mathrm{Co}$, and Ni). J. Phys. Chem. A 107, 2716-2729 (2003).

54. Yokota, Y. et al. Computational investigations of electronic structure modifications of ferrocene-terminated self-assembled monolayers: effects of electron donating/withdrawing functional groups attached on the ferrocene moiety. Phys. Chem. Chem. Phys. 19, 32715-32722 (2017).

55. Yokota, Y. et al. Electronic-state changes of ferrocene-terminated selfassembled monolayers induced by molecularly thin ionic liquid layers: A combined atomic force microscopy, X-ray photoelectron spectroscopy, and ultraviolet photoelectron spectroscopy study. J. Phys. Chem. C. 119, 18467-18480 (2015)

56. Wong, R. A., Yokota, Y., Wakisaka, M., Inukai, J. \& Kim, Y. Discerning the redox-dependent electronic and interfacial structures in electroactive selfassembled monolayers. J. Am. Chem. Soc. 140, 13672-13679 (2018).

57. Hirata, N., Shibuta, M., Eguchi, T. \& Nakajima, A. Excited electron dynamics at ferrocene-terminated self-assembled monolayers on $\mathrm{Au}$ (111) Lengthened lifetime of image potential state. Chem. Phys. Lett. 561, 131-136 (2013).

58. Pletcher, D. A First Course in Electrode Processes (Royal Society of Chemistry, London, 2019).

59. Calvente, J. J., Andreu, R., Molero, M., López-Pérez, G. \& Domínguez, M. Influence of spatial redox distribution on the electrochemical behavior of electroactive self-assembled monolayers. J. Phys. Chem. B 105, 9557-9568 (2001).

60. Borup, R., Sauer, D. \& Stuve, E. An ex situ study of electrodeposited lead on platinum (111): I. Examination of the surface redox behavior of lead and dynamic emersion. Surf. Sci. 293, 10-26 (1993).

61. Kolb, D. \& Michaelis, R. Influence of the surface electric field on the electronic states of an adsorbate. J. Electroanal. Chem. Interfacial. Electrochem. 284, 507-510 (1990).

62. Lazarescu, V. On the significance of the core level binding energy shifts observed in the XPS measurements on emersed electrodes. J. Electron. Spectrosc. Relat. Phenom. 104, 41-45 (1999).

63. Mondal, P. C., Chhatwal, M., Jeyachandran, Y. L. \& Zharnikov, M. Enhancement of optical and electrochemical properties via bottom-up assembly of binary oligomer system. J. Phys. Chem. C. 118, 9578-9587 (2014)

64. Vogel, Y. B. et al. Reproducible flaws unveil electrostatic aspects of semiconductor electrochemistry. Nat. Commun. 8, 2066 (2017).

65. Sano, H. et al. Formation of uniform ferrocenyl-terminated monolayer covalently bonded to $\mathrm{Si}$ using reaction of hydrogen-terminated $\mathrm{Si}$ (111) surface with vinylferrocene/n-decane solution by visible-light excitation. $J$. Colloid Interface Sci. 361, 259-269 (2011).

66. Ohtake, T. \& Tanaka, H. Redox-induced actuation in macromolecular and self-assembled systems. Polym. J. 48, 25-37 (2016).

67. Bachman, J. C. et al. Electrochemical polymerization of pyrene derivatives on functionalized carbon nanotubes for pseudocapacitive electrodes. Nat. Commun. 6, 1-9 (2015)

68. Angerstein-Kozlowska, H., Conway, B., Hamelin, A. \& Stoicoviciu, L. Elementary steps of electrochemical oxidation of single-crystal planes of $\mathrm{Au}$ Part II. A chemical and structural basis of oxidation of the (111) plane. J. Electroanal. Chem. Interfacial. Electrochem. 228, 429-453 (1987).

69. Faisal, F. et al. Electrifying model catalysts for understanding electrocatalytic reactions in liquid electrolytes. Nat. Mater. 17, 592-598 (2018).

70. Scofield, J. H. Hartree-Slater subshell photoionization cross-sections at 1254 and 1487 eV. J. Electron Spectrosc. Relat. Phenom. 8, 129-137 (1976). 


\section{Acknowledgements}

This work is supported by (1) Japan Science and Technology Agency (JST) under the ACCEL project entitled "Fundamental and Applications of Diamond Electrodes", (2) Grants-in-Aid for Scientific Research (KAKENHI) no. JP19H02695 and (3) FY2018 RIKEN Incentive Research Projects. We thank Prof. Y. Einaga (Keio University) for helpful discussions.

\section{Author contributions}

R.A.W. and Y.Y. designed the experiments and interpreted the results. R.A.W. performed the experiments. M.W. and J.I. provided expertise concerning the construction of the ECXPS/UPS setup. Y.Y. and Y.K. supervised the research. All of the authors discussed the results and final paper.

\section{Competing interests}

The authors declare no competing interests.

\section{Additional information}

Supplementary information is available for this paper at https://doi.org/10.1038/s41467020-18030-6

Correspondence and requests for materials should be addressed to Y.Y. or Y.K.
Peer review information Nature Communications thanks Takuya Masuda, and the other, anonymous, reviewer(s) for their contribution to the peer review of this work.

Reprints and permission information is available at http://www.nature.com/reprints

Publisher's note Springer Nature remains neutral with regard to jurisdictional claims in published maps and institutional affiliations.

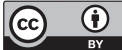

Open Access This article is licensed under a Creative Commons Attribution 4.0 International License, which permits use, sharing, adaptation, distribution and reproduction in any medium or format, as long as you give appropriate credit to the original author(s) and the source, provide a link to the Creative Commons license, and indicate if changes were made. The images or other third party material in this article are included in the article's Creative Commons license, unless indicated otherwise in a credit line to the material. If material is not included in the article's Creative Commons license and your intended use is not permitted by statutory regulation or exceeds the permitted use, you will need to obtain permission directly from the copyright holder. To view a copy of this license, visit http://creativecommons.org/ licenses/by/4.0/.

(C) The Author(s) 2020 